\title{
The Linguistic Basis of Text Generation
}

\author{
Laurence Danlos \\ Laboratoire d'Automatique Documentaire et Linguistique \\ Universite Paris 7 \\ 2, Place Jussieur (Tour Centrale, 9 etage) \\ F-75251 Paris Cedex 05, FRANCE
}

This presentation was based on a book, The Linguistic Basis of Text Generation, recently published by Cambridge University Press (Cambridge, England, 1987) in the series Studies in Natural Language Processing sponsored by the Association for Computational Linguistics. An abstract for the book follows.

\footnotetext{
ABSTRACT

This study presents an original and penetrating analysis of the complex problems surrounding the automatic generaton of natural language text. Laurence Danlos provides a valuable critical review of current research in this important and increasingly active field, and goes on to describe a new theoretical model that is thoroughly grounded in linguistic principles.

The model emphasizes the semantic, syntactic and lexical constraints that must be dealt with when establishing a relationship between meaning and form, and it is consideration of such linguistic constraints that determines Danlos' generation algorithm. The book concludes with a description of a generation system based on this algorithm which produces texts in several domains and also a system for the synthesis of spoken messages from semantic representations.

The book is a significant addition to the literature on text generation, and will be of particular interest to all computational linguists and AI researchers who have wrestled with the problem of vocabulary selection.
} 